Revista General de Información y Documentación ISSN: $1132-1873$

https://dx.doi.org/10.5209/rgid.70068

\title{
Los Archivos Históricos Provinciales y la valoración documental en España
}

\author{
Carlos Flores Varela ${ }^{1}$
}

Recibido: 9 de enero de 2020 / Aceptado: 29 de marzo de 2020

Resumen. El artículo analiza el papel de los Archivos Históricos Provinciales (AHP) en los mecanismos de valoración documental en España, tanto en la Administración General del Estado como en las Comunidades Autónomas. Se estudia la presencia de los AHP en los órganos de valoración, su peso en el conjunto de series documentales valoradas y, cuando es posible, las consecuencias en cuanto a volumen de documentación eliminada.

Palabras clave: archivos; valoración documental; comisiones calificadoras de documentos; archivos históricos provinciales; sistemas archivísticos.

\section{[en] Provincial Historical Archives and Documentary Appraisal in Spain}

\begin{abstract}
The article analyzes the role of the Provincial Historical Archives (AHP) in the mechanisms of documentary appraisal in Spain, both in the General State Administration and in the Autonomous Communities. The presence of the AHPs in the evaluation committees, their weight in the set of assessed documentary series and, when possible, the consequences in terms of volume of eliminated documentation are studied.
\end{abstract}

Keywords: archives; archival appraisal; document assessment commitees; provincial historical archives; archival systems.

Sumario. 1. Introducción. 2. Los AHP en la CSCDA. 3. En las CCAA. 4. Conclusiones. 5. Referencias bibliográficas.

Cómo citar Flores Varela, C. (2020) Los Archivos Históricos Provinciales y la valoración documental en España, en Revista General de Información y Documentación 30 (1), 11-39.

\section{Introducción}

Los Archivos Históricos Provinciales (AHP) son los depositarios de la documentación considerada de conservación permanente producida por las administraciones periféricas tanto del Estado como de las Comunidades

1 Filiación: Archivo Histórico Provincial de Toledo.

E-mail; jfloresv@jccm.es 
Autónomas. Así se establece en el art. 12.2 del RD 1708/2011, que regula el Sistema Español de Archivos, y en buena parte de la normativa autonómica equivalente, como el art. 25 de la Ley 19/2002 de Archivos Públicos de Castilla-La Mancha. Por tanto, los AHP son elemento fundamental de cualquier sistema de valoración documental. Sin embargo, como veremos, su participación en los órganos decisorios en esta materia es muy irregular tanto en su distribución geográfica como temporal. El propósito de este trabajo es, pues, estudiar con detalle el papel real que los AHP desempeñan dentro de los mecanismos de valoración documental en España. Espero demostrar que estos archivos se encuentran infrarrepresentados en estos mecanismos de valoración documental, pese a ser los destinatarios finales de una parte importante de la documentación afectada.

\section{Los AHP en la CSCDA}

Empezaremos, pues, analizando la participación de los AHP en el órgano de valoración de la Administración General del Estado, la Comisión Superior Calificadora de Documentos Administrativos (CSCDA), adscrita teóricamente al Ministerio de la Presidencia a través de la Comisión de Archivos de la Administración General del Estado. Pero, puesto que esta Comisión de Archivos de la AGE no se ha llegado a constituir, o al menos no he conseguido encontrar rastro alguno de su actividad, la CSCDA en la práctica funciona adscrita al Ministerio de Cultura y Deportes. De hecho, sus reuniones han venido siendo presididas por un director general u órgano equivalente de este último Ministerio, y su secretaría la ejerce la Subdirección General de Archivos Estatales.

Para el análisis que nos ocupa ahora he utilizado, además de la base de datos del BOE para localizar la legislación, la página web de la CSCDA². En concreto, su sección "Documentos", donde se encuentran las actas de todas las sesiones celebradas hasta el momento así como la lista de las series documentales dictaminadas, con un buscador que facilita mucho la tarea. Solo falta el acta de la última sesión, celebrada en julio de 2019, que aún no tiene carácter definitivo.

La CSCDA se apoya en última instancia en el art. 58 de la Ley 16/1985, de 25 de junio, del Patrimonio Histórico Español (LPHE). El primer desarrollo de esta cuestión, sin embargo, tardó en llegar quince años, hasta el RD 139/2000, de 4 de febrero. Entre los miembros natos de esta primera versión de la CSCDA no se incluye ningún director de AHP, aunque podría ocurrir que hubiese algunos entre los cinco vocales designados libremente por el Ministerio; enseguida veremos que no es así. Lo que sí queda claro es que la CSCDA dictaminará sobre los plazos de permanencia y las transferencias de los documentos entre los distintos tipos de archivo: de oficina o gestión, central, intermedio e histórico. El RD 1164/2002, de 8 de noviembre, que detalla el procedimiento de valoración, establece que este procedimiento solo lo podrán iniciar las Comisiones Calificadoras de los

http://www.culturaydeporte.gob.es/cultura/areas/archivos/mc/cscda/inicio.html [Consulta 4/10/2019]. 
Ministerios o equivalentes, a iniciativa de ellas mismas o "de los órganos responsables de los documentos o series documentales concernidas". Igualmente, solo se contempla la valoración con vistas a la eliminación o al cambio de soporte. Los primeros vocales de libre designación no se nombraron hasta junio de $2003^{3}$ y entre ellos no había ningún representante de AHP; de hecho, no había ningún archivero.

Esta Comisión se reunió dos veces en 2003, obviamente sin la presencia de ningún director de AHP, y se dedicó a cuestiones de orden metodológico y de funcionamiento; es decir, que no aprobó ninguna propuesta de valoración. Después sufrió un parón en su ritmo de sesiones hasta retomarlo en junio de 2006, con sucesivas reuniones en febrero y junio de 2007. Pero en febrero de 2007 se publicó un nuevo decreto sobre el funcionamiento de la CSCDA, que será el que rija hasta hoy. Aunque, en principio y según su propia Exposición de Motivos, su propósito era simplemente incorporar a todos los Ministerios y constituir una Comisión Permanente, en realidad para nuestro tema supuso un importante avance. En efecto, su art. 3.2 establece la posibilidad de crear Subcomisiones del Pleno que, a su vez, podrán estar asesoradas por "archiveros que desarrollen sus funciones en cualesquiera de los archivos de titularidad estatal”, lo que abría la puerta a la participación de archiveros de los AHP, sin cerrar la posibilidad de ser designados libremente por el Ministro de turno. No obstante, no tengo noticia de que se creasen tales subcomisiones en aquellos momentos, de manera que la participación de los AHP siguió quedando restringida, de hecho, a la designación de alguno de sus directores, posibilidad que aún no se vería realizada, porque entre los nuevos vocales de libre designación, nombrados en febrero de $2006^{4}$, no había ningún representante de los AHP; eso sí, al menos esta vez se incorporaron dos archiveros: uno municipal y otro de una fundación cultural pública.

LA CSCDA no ha modificado este esquema legal en lo que a nosotros concierne. Por su parte, los vocales de libre designación se han venido renovando desde entonces con regularidad, pero solo en octubre de 2010 encontramos por primera vez a una representante de AHP, en concreto Eva Merino Flecha, directora del AHP de León ${ }^{5}$, que en 2015 sería sustituida por Riansares Serrano Morales, entonces en el AHP de Guadalajara ${ }^{6}$ y en 2017 por el autor de estas líneas ${ }^{7}$. De este modo, en la última década de funcionamiento de la CSCDA ha habido una especie de tradición de contar con un director o directora de AHP. Pero no olvidemos que esta presencia es puramente discrecional, por nombramiento del Ministro correspondiente que, como es lógico, suele seguir las propuestas del Subdirector de Archivos Estatales.

En la práctica, la primera reunión a la que asistió de manera efectiva un representante de AHP fue la de octubre de 2012, con presencia de la mencionada Eva Merino, que sería también quien protagonizara la primera aparición de estos

\footnotetext{
Orden ECD/1853/2003

Orden CUL/525/2006

Orden CUL 2736/2010

Orden ECD/2438/2015

Orden ECD/1170/2017
} 
centros en las actas de la CSCDA, precisamente sobre la forma de presentar peticiones de dictamen. Esta intervención tendría lugar en mayo de 2013, y quizá podamos detenernos un momento en esta reunión porque se trataron cuestiones que tendrían luego su recorrido. En efecto, el subdirector de Archivos Estatales respondió a la pregunta indicando que la petición de dictamen la pueden realizar los propios AHP a la Secretaría de la Comisión a través de las respectivas comunidades autónomas, si bien no especificó en qué precepto legal se basaba para establecer tal procedimiento. Por su parte, la Secretaria de la Comisión, Beatriz Franco, apuntó que, para que los AHP pudieran ejecutar las disposiciones ya aprobadas, deberían dirigirse a ella misma, quien "se pondría en contacto con el órgano proponente de la resolución, enviará la resolución al archivo con copia a la comisión o grupo de trabajo proponente y el Archivo tiene que actuar siguiendo el procedimiento establecido, eliminando la documentación de una manera segura y enviando un acta de eliminación a la Secretaría de la CSCDA" ${ }^{8}$. Además, se establece que la aprobación de las aplicaciones de eliminación en función de dictamen previo quede delegada en la Comisión Permanente de la CSCDA. En fin, el subdirector de Archivos Estatales comenta también que será necesaria la convergencia entre los grupos de trabajo de la CSCDA y los que puedan formarse en el Consejo de Cooperación Archivística próximo a constituirse. Lo cierto es que no puede evitarse la sensación de que este procedimiento tenía mucho de improvisado.

Sin embargo, improvisado o no, los AHP lo aprovecharon rápidamente. El siguiente cuadro resume las propuestas de valoración que los AHP presentaron, utilizando este procedimiento algo retorcido, entre 2013 y 2015:

- Reunión de diciembre de 2013:

- Se informó de la aprobación el mes anterior de la eliminación de seis series de los AHP de Sevilla, Cádiz y Málaga. Esta fue la primera eliminación regulada de documentos que se ha realizado en los AHP españoles.

- Se planteó un debate sobre los expedientes de extranjería en cuyos pormenores no entraré ahora, pero sí señalaré que, según el acta, en ella intervinieron los representantes del Ministerio del Interior y del Ministerio de Hacienda y Administraciones Públicas, además del propio Subdirector de Archivos Estatales, pero no la directora de AHP presente, a pesar de que estos documentos irían a parar a nuestros centros.

- Y también es interesante reproducir literalmente lo que dice el acta respecto al final de esta discusión: " $\mathrm{D}$ a Rosana de Andrés señala que [...] el Ministerio del Interior no va a incluir en ella [la Resolución que permite la ejecución del acuerdo de valoración en cuestión], como debería, la documentación de los Gobiernos Civiles y esto es algo que ruega que la Subdirección General de los Archivos Estatales tenga presente, porque es la

8 El acta de esta reunión puede encontrarse en http://www.culturaydeporte.gob.es/dam/jcr:c44598c9-83dc-493aaa56-2841fa240ec2/acta13-pdf.pdf. [Consulta 04/10/2019]. 
unidad que coordina a los Archivos Históricos Provinciales que custodian los fondos documentales de los Gobiernos Civiles. D. Severiano Hernández señala que cualquier cuestión relacionada con los Archivos Históricos Provinciales tiene que estar canalizada a través de la Subdirección General de los Archivos Estatales”.

- Reunión de junio de 2014

- Los AHP han presentado en la Comisión Permanente de la CSCDA y a través de los correspondientes Ministerios, hasta doce propuestas de eliminación, de un total de 26. Sin embargo, finalmente solo se aprobaron cinco propuestas: tres de Málaga y dos de Córdoba.

- Se informa que desde 2008 las resoluciones de valoración de la Agencia Tributaria mencionan específicamente la documentación depositada en los AHP, por lo que estos pueden también eliminar esta documentación sin más trámite que informar posteriormente a la CSCDA. Es un primer paso hacia la simplificación de la eliminación documental en los AHP.

- El Ministerio de Trabajo y Seguridad Social pide que la Subdirección de Archivos Estatales recuerde a todos los AHP su obligación de recoger la documentación que cumpla las condiciones de transferencias, en su condición de archivos intermedios para los servicios periféricos del Estado.

- El mismo Ministerio pide que se transmita a las CCAA la necesidad de unidad de criterio en series correspondientes a transferencias de competencias, puesto que las comisiones autonómicas, en algunas ocasiones, han dictaminado sobre documentación producida por los órganos periféricos de la AGE.

- Sobre estas dos últimas cuestiones, la subdirección señala que "por parte de los Archivos Históricos Provinciales hay falta de comunicación”, lo que hace que no se puedan hacer planificaciones de obras. Igualmente "quiere dejar claro que la documentación estatal es la titular en estos archivos, y que la documentación autonómica está en ellos en depósito. En la próxima reunión [del Consejo de Cooperación Archivística] va a tratarse este tema, así como que todas las relaciones que se hagan con dichos archivos tienen que hacerse a través del Departamento de Estado de Cultura [sic]”10.

- Reunión de diciembre de 2014:

- Se aprueban dos peticiones de ejecución de dictamen previo, ahora del AHP de Almería.

$9 \quad$ El acta, en http://www.culturaydeporte.gob.es/dam/jcr:db5d96fa-62bd-4621-a974-d3f509a3a26a/acta14pdf.pdf. [Consulta: 04/10/2019]. La cursiva es mía.

10 El acta, en http://www.culturaydeporte.gob.es/dam/jcr:9bef83eb-274e-438e-ba28-aad48f246385/acta-15.pdf. [Consulta: 04/10/2019] 
- En la aprobación de la eliminación de la serie de "Recursos de reposición del Catastro", Eva Merino plantea una cuestión sobre los documentos más antiguos que pueden contener estos expediente, siendo respondida por la archivera del Ministerio de Hacienda y por el subdirector de Archivos Estatales.

- Reunión de julio de 2015:

- Se presentan por primera vez peticiones de valoración (no de ejecución), en concreto del AHP de Cádiz, lo que es puesto de relieve de manera general, puesto que abren la vía a que otros AHP pidan la ejecución de las mismas.

- Se modifica un dictamen sobre autorizaciones de trabajo y residencia a extranjeros, modificando los plazos para que los documentos que lleguen a los AHP lo hagan ya valorados.

- Reunión de diciembre de 2015: no acude ningún director de AHP ni se trata ningún asunto relacionado con ellos, salvo informar del nombramiento de Riansares Serrano como vocal de libre designación.

Es decir, que durante los dos primeros años de presencia real de los AHP en la CSCDA solo se aprobaron peticiones de ejecución de valoraciones presentadas por otros órganos y que afectaban a los AHP, y todas ellas presentadas por archivos específicos. Solo en julio de 2015 se presentaron propuestas de valoración a iniciativa de AHP, pero de nuevo con valor únicamente para el archivo proponente. Es importante destacar que, entre las funciones que el Real Decreto del Sistema Español de Archivos atribuye a los archivos intermedios está "identificar y llevar a cabo procesos de valoración documental [...]"11. Además, se observa que se aprovechan las reuniones de la Comisión para plantear cuestiones que van más allá de la valoración, y que apuntan a la peculiar situación administrativa de los AHP o, dicho de otro modo, a la pugna entre el Estado, representado por el Ministerio responsable de cultura, y las Comunidades Autónomas, pugna sobre la que no debemos hacer ahora mayores averiguaciones.

La reunión de julio de 2016 resulta especialmente importante para nosotros, sobre todo porque en ella se informa de la constitución, dentro del Consejo de Cooperación Archivística, de una Comisión de AHP y, a su vez, dentro de esta, un Grupo de Trabajo sobre Valoración. Este grupo de trabajo (GT), del que hablaré más adelante, permitirá, por un lado, realizar peticiones de dictamen que afecten a todos los AHP y, por otro lado, mejorar la coordinación y comunicación con las comisiones de valoración de las comunidades autónomas. Por lo demás, en relación con la titularidad de la documentación judicial prescrita, se pide a los AHP información (la palabra está omitida en el acta, sin duda por error no subsanado) sobre el volumen de transferencias de la Administración de Justicia, sin la cual "no 
se puede hacer ningún tipo de planificación en materia de infraestructuras, cuyos gastos recaen en el Ministerio de Educación, Cultura y Deportes” ${ }^{\text {”2 }}$; esta anotación es reveladora de la naturaleza de las tensiones entre el Estado y las Comunidades Autónomas en este asunto. Pero todo esto no fue obstáculo para que se presentasen nuevas peticiones de dictamen (cuatro de Cádiz, una de Murcia y otra de Málaga), dos autorizaciones de ejecución por disposición previa, ambas de Murcia, y cuatro dictámenes presentados por el Ministerio de Hacienda y Administraciones Públicas, adaptados para que puedan acogerse a ellos todos los AHP. Es decir, que por encima, o por debajo, de los debates entre administraciones, reflejados en las actas de la CSCDA, los archiveros de los AHP seguían exprimiendo todo lo posible los resquicios de posibilidades de valoración documental que se les permitía utilizar. Pero, a partir de aquí, con la constitución de un Grupo de Trabajo específico, la situación mejora ostensiblemente, sobre todo porque ya se permite la presentación de propuestas de valoración que pueden ser aplicadas a todos los AHP y no solo al proponente. Desde aquí, la actividad de los AHP en las reuniones de la CSCDA ha sido la siguiente:

- Reunión de marzo de 2017:

- Se presentan las propuestas del GT, válidas para todos los AHP. Son 11 series en total, de las que ocho corresponden a series que ya habían sido presentadas y aprobadas, pero solo para los AHP que lo solicitaron.

- La Secretaria del GT, que lo era también de la CSCDA, Beatriz Franco, informa de las actividades del grupo. Además de presentar las solicitudes de dictamen y anunciar las próximas, informa de la consulta a la Abogacía del Estado sobre la forma de proceder con la documentación electoral. El resultado de esta consulta es que ni la CSCDA ni las Juntas de Expurgo judiciales son competentes sobre la documentación electoral, con lo que habrá que arbitrar algún tipo de colaboración.

- Se hace eco de la preocupación de la Comisión de AHP en su conjunto por la documentación judicial, y también se recuerda el problema de la documentación catastral

- Reunión de diciembre de 2017:

- Se presentan cuatro propuestas del GT de AHP.

- Se informa sobre la actividad del GT en general.

- Se pregunta por el espacio libre en los AHP, la Subdirección responde que la falta de coordinación hace imposible saberlo, a lo que hay que sumar "la transferencia de documentación judicial”.

12 El acta, en http://www.culturaydeporte.gob.es/dam/jcr:c49d0e33-0303-4a96-9ed8-162629219d8c/acta-19.pdf. [Consulta 04/10/2019]. 
- Reunión de noviembre de 2018:

- En el saludo del vicepresidente se alude a las conversaciones sobre el tratamiento de la documentación electoral, especificando que una solución a este problema permitiría liberar un "gran espacio" en los AHP.

- Se presentan dos propuestas por parte del GT.

- Se informa del funcionamiento general del GT. Su funcionamiento se ha visto afectado por las reestructuraciones ministeriales.

- Se informa de las conversaciones sobre el tratamiento documental de la documentación electoral, sin nada concreto.

Falta el acta de la reunión del pasado mes de julio de 2019. En total, pues, el Grupo de Trabajo de AHP ha presentado 17 propuestas de dictamen en los casi tres años que lleva funcionando, de las que ocho corresponden a series ya dictaminadas pero solo para el AHP que las propuso: es decir, que de algún modo son repeticiones. Además, entre 2013 y 2017 se habían aprobado 16 peticiones de dictamen, de las que cinco son adaptaciones de dictámenes para ser utilizados por todos los AHP, además de dos solicitudes de ejecución de dictámenes previos, sin contar la autorización general relativa a las series de la AEAT. En total, 33 solicitudes de dictamen, 29 si contamos solo las que son auténticas solicitudes de dictamen o de adaptación de dictámenes previos.

Si ponemos estas cifras en relación con el total de series valoradas, el resultado es aparentemente desalentador: las series presentadas por los AHP son apenas el $2,75 \%$ del total de series valoradas. Pero hay que tener en cuenta que los AHP solo entraron en la Comisión en 2010, e incluso que hasta 2015 no empezaron a proponer valoraciones, bien directamente, bien a través de los Ministerios. Y solo en 2017 aparecen propuestas de dictamen procedente del Grupo de Trabajo. Si contamos solo los años en que los AHP están presentes de algún modo, el porcentaje de series presentadas sube hasta el $6 \%$, y si nos fijamos solo en los años de funcionamiento del GT, llegamos al $15 \%$. Esto nos indica que el ritmo de presentación de propuestas de valoración está creciendo de manera exponencial en cuanto se han establecido cauces eficaces para la participación activa de los AHP en la CSCDA. Habrá que esperar a los próximos años para ver cómo evoluciona esta participación de nuestros centros en esta Comisión.

Pero podemos avanzar un poco más. En efecto, no solo las series documentales presentadas por los AHP directa o indirectamente afectan a nuestros centros. Frecuentemente las presentadas por los Ministerios o por otros grupos de trabajo señalan la documentación que ya no debe estar en los AHP o que nunca deberá llegar a ellos. Para localizar estas series, me he fijado en la publicación de las correspondientes Resoluciones de los diferentes Ministerios, que son las que dan fuerza ejecutiva a las decisiones de la $\operatorname{CSCDA}^{13}$. Hasta la fecha, tengo contabilizadas un total de 337 series

13 La web de los archivos de Castilla y León publica un muy útil listado de estas disposiciones, pero desgraciadamente se queda en 2016: 
que, de una forma u otra, afectan a los AHP, desde 2006 hasta fin de 2019. De ellas, solo nueve se han declarado de conservación permanente; el resto, en general, son de eliminación total, a veces a partir de una fecha determinada y casi siempre con la obligación de dejar una muestra. Como hemos visto, esto no significa que los AHP puedan eliminar esta documentación sin más trámite que su comunicación a la CSCDA, sino que deberían elaborar una propuesta de ejecución. Significativamente, desde que se puso en marcha el Grupo de Trabajo no se ha presentado ninguna propuesta de ejecución, cuando en el período 2013-2016 se presentaron diez, cuatro de ellas repetidas en AHP distintos. Esto puede explicarse porque el Grupo de Trabajo ha asumido y presentado las propuestas que ya habían sido presentadas previamente por AHP concretos, como las relacionadas con los cuestionarios para la elaboración de los censos de población y edificios de 1970 y 1980.

Tenemos datos sobre la consecuencia práctica de todo esto, es decir, sobre el volumen de documentación efectivamente eliminada por los $\mathrm{AHP}^{14}$. He recopilado los datos solo desde 2010 y hasta 2018, y también hay que advertir que se trata de las cifras que maneja la propia CSCDA sobre la base de las notificaciones que deben enviar los archivos cuando eliminan documentación, por lo que cabe la posibilidad de que no siempre esta notificación se haya producido. Con estas prevenciones, he podido elaborar el siguiente gráfico:

Tabla 1: Documentación eliminada por los AHP

\begin{tabular}{|r|r|r|}
\hline Año & Volumen (m.l.) & Series (acumulado) \\
\hline & & \\
\hline 2010 & 20,5 & \\
\hline 2011 & 427,62 & \\
\hline 2012 & 0 & \\
\hline 2013 & 103,5 & \\
\hline 2014 & 2423,91 & 2 \\
\hline 2015 & 281,46 & 12 \\
\hline 2016 & 83,8 & 27 \\
\hline 2017 & 556,92 & 29 \\
\hline 2018 & 406,64 & \\
\hline
\end{tabular}

Estos datos nos indican que, salvo el año 2014, todos los demás años apenas se ha conseguido llegar a 500 metros de documentación eliminada, sin que parezca que el número de series valoradas afecte a esta tendencia que podríamos llamar “plana”. En cuanto al año 2014, más de 2.000 m.l. del total fueron eliminados por

https://archivoscastillayleon.jcyl.es/web/jcyl/ArchivosCastillaYLeon/es/Plantilla100/1284793335566/_/__ [Consulta 3/12/2019].

14 Estos datos me han sido proporcionados amablemente por Ricard Pérez Alcázar, secretario de la CSCDA, a quien le agradezco mucho su ayuda. 
el AHP de Málaga, es decir, que se trató de una circunstancia absolutamente puntual. Podemos añadir otro matiz si observamos qué archivos son los que han realizado estas eliminaciones. En primer lugar, Málaga y Cádiz, con cinco eliminaciones cada uno; les siguen Segovia, Almería y Ciudad Real, que han eliminado en tres ocasiones; dos veces lo han hecho Toledo y Murcia y una Guadalajara, Valencia y Sevilla. Es decir, diez archivos de una nómina total de 49, menos del 20,5 \%. Si hacemos la distribución por comunidades autónomas, encontramos que solo cinco comunidades han hecho uso de la posibilidad de eliminar documentación estatal. La más activa, sin duda, es Andalucía, con 14 eliminaciones, seguida muy de lejos por Castilla-La Mancha con seis y Castilla y León con tres. Murcia y Valencia solo lo han hecho en una ocasión. Evidentemente, no es lo mismo el número de eliminaciones que podría realizar una comunidad autónoma con ocho provincias que otra con una. Pero si dividimos el número de eliminaciones por el de provincias, el resultado es muy similar: Andalucía llega a 1,75 eliminaciones por archivo, Castilla-La Mancha hasta las 1,2 eliminaciones por archivo, Murcia una, mientras que Valencia y Castilla y León se quedan con apenas 0,33 eliminaciones por archivo. Si tenemos en cuenta que las eliminaciones de Castilla y León se refieren exclusivamente al AHP de Segovia y tuvieron lugar antes de 2015, podemos concluir que solo las comunidades de Castilla-La Mancha y Andalucía están utilizando la valoración de documentos estatales para aliviar la presión de los depósitos de sus archivos.

En realidad, por debajo de estos cálculos, quizá algo alambicados, encontramos la evidencia de que las eliminaciones responden a la voluntad personal de determinados centros, es decir, de sus respectivos directores. Diez de las catorce eliminaciones de Andalucía se concentran en Málaga y Cádiz, que son también los centros que mayor número de propuestas de valoración y/o de ejecución de valoración han presentado a la CSCDA, y en esa Comunidad solo les acompaña Almería. En Castilla-La Mancha, dos de sus cinco provincias no han realizado eliminación alguna. Incluso en el caso castellano-leonés se puede apreciar una coincidencia entre la llegada de su actual directora al archivo de Segovia y la paralización de las eliminaciones de documentación. Quizá se trate de un problema de comunicación entre la CSCDA y los AHP, salvo que tengamos que pensar que estos últimos, que reiteradamente se quejan de falta de espacio, estén mostrando una enorme incoherencia al no aprovechar las todavía escasas, pero ya existentes, oportunidades para eliminar algo de documentación. Puede que la puesta en marcha del Grupo de Trabajo de AHP dentro de la CSCDA contribuya a mejorar esta situación, pero, como ya he señalado, todavía es pronto para evaluar su funcionamiento.

Si de todo esto hay que extraer una reflexión general, solo se me ocurre que la relación del órgano supremo de calificación de documentos del Estado y los AHP puede resumirse en un largo olvido hasta tiempos recientes, lo que se suma a la inexplicable tardanza en poner en marcha un mecanismo real de valoración documental en el Estado. Desde que la LPHE ordenó su instauración, la CSCDA ha tardado la friolera de 21 años en constituirse de manera efectiva (Conde Villaverde, 2016: 135). Después, otros cuatro años para acordarse de la existencia de los AHP — que, no lo olvidemos, son archivos de titularidad estatal y que 
custodian fundamentalmente documentación estatal—, tres más para que empezaran a aparecer propuestas de valoración desde estos archivos y otros cuatro aún para encontrar un mecanismo relativamente ágil y eficaz para presentar estas propuestas. Ahora, es verdad, sí que los AHP pueden presentar sus propuestas, esperar que sus series sean valoradas en un plazo razonable y aliviar un poco sus sobrecargados depósitos. Pero ha sido necesario esperar 32 años para ello, toda una vida administrativa.

\section{En las CCAA}

Una vez analizada la presencia de los AHP en el órgano de valoración de la Administración General del Estado, podemos pasar a hacer lo propio en las Comunidades Autónomas. En primer lugar, realizaré un estudio paralelo al realizado para el Estado, es decir, sobre la presencia de los AHP en los órganos de valoración. En segundo lugar, profundizaré un poco más sobre el número de series valoradas e incluso, en la única Comunidad Autónoma en que esto es posible, sobre el volumen de documentación eliminada en nuestros centros.

\subsection{La presencia de los AHP en los órganos de valoración}

Para la elaboración de este apartado me he basado en la lista de legislación archivística que proporciona la asociación "Archiveros Españoles en la Función Pública” en su página web ${ }^{15}$. Para localizar las actas de reuniones de las correspondientes comisiones, o las listas de series valoradas, he utilizado los portales de archivos de cada comunidad autónoma, cuando existen. En cuanto a la bibliografía, el único estudio general que conozco respecto de estas comisiones y de su funcionamiento en el conjunto de España es el de Alfonso Ruiz Cagigal (2017), aunque está muy centrado en la valoración de fondos municipales de la Comunidad de Madrid, justo la única comunidad en que no podemos considerar que exista un AHP. Además, hay alusiones ejemplares de carácter sectorial en la obra de González Corral (2012: 189-190). Respecto de comisiones autonómicas, las mejor representadas son Cataluña (Cermeno Martorell, 2003; Tarraubella i Mirabet, 2003; Cermeno Martorell, 2012) y Andalucía (Díaz Díaz, 2010; Páez García, 2010). Encontramos también trabajos sobre las comisiones de Galicia (López Fernández; Rodríguez-Segade Vázquez, 2018), Castilla y León (Garmendia Ruiz, 2000) y Asturias (Archivo General de la Administración del Principado de Asturias, 2018). En general, estos trabajos se centran en cuestiones metodológicas y de criterios generales de actuación, con escasos datos cuantitativos sobre su funcionamiento, salvo algunas excepciones que serán utilizadas en su momento. Por tanto, será necesario aquí ofrecer, siquiera de forma breve y superficial, algunos datos sobre las distintas formas de afrontar la valoración en las distintas 
comunidades autónomas, para enseguida entrar a analizar su relación con los correspondientes AHP.

Las Comisiones Calificadoras de las CCAA están apoyadas legalmente en el art. 55.1 de la Ley del Patrimonio Histórico Español, que reza: "La exclusión o eliminación de bienes del Patrimonio Documental y Bibliográfico contemplados en el artículo 49.2 y de los demás de titularidad pública deberá ser autorizada por la Administración competente”. Obsérvese que esta redacción no implica que necesariamente deba existir una comisión, sino solo que debe existir autorización formal de la Administración competente. No obstante, como veremos, la gran mayoría de comunidades han afrontado la valoración documental sobre la base de comisiones calificadoras, evaluadoras o de denominación similar.

Por lo demás, y como es lógico, la valoración documental en las CCAA se fundamenta en sus respectivas leyes de archivos o leyes equivalentes. Todas ellas dejan claro que la "administración competente" para todos los documentos ubicados en su territorio es la autonómica, excepto para los documentos de titularidad estatal. El siguiente cuadro-resumen nos muestra el año y la disposición legal de creación de las comisiones calificadoras en cada Comunidad Autónoma, así como si en estas disposiciones se contempla expresamente la presencia de los AHP. En algunos casos, estas comisiones han debido ser completamente reestructuradas por diferentes circunstancias, que pueden resumirse en dos: un cambio legislativo importante o, con mayor frecuencia, su escasa o incluso nula actividad; por eso, algunas comunidades cuentan con dos o más disposiciones de creación, o re-creación, de estas comisiones calificadoras.

Tabla 2: Normas de creación de las comisiones calificadoras autonómicas

\begin{tabular}{|c|c|c|c|}
\hline & Año de creación & Norma de creación & ¿Hay AHP? \\
\hline \multirow{3}{*}{ Andalucía } & 1994 & D. $73 / 1994$ & Sí \\
\hline & 2000 & D. $97 / 2000$ & Sí \\
\hline & 2011 & L. 7/2011 & Sí \\
\hline Aragón & 1993 & D. $12 / 1993$ & No \\
\hline Asturias & 1996 & D. $21 / 1996$ & No \\
\hline \multirow{3}{*}{ Islas Baleares } & 1987 & D. $14 / 1987$ & No \\
\hline & 2006 & L. $15 / 2006$ & No \\
\hline & 2010 & D. $99 / 2010$ & Sí \\
\hline Islas Canarias & 2003 & D. $76 / 2003$ & No \\
\hline \multirow[t]{2}{*}{ Cantabria } & 2000 & D. $7 / 2000$ & Sí \\
\hline & 2002 & L. 3/2002 & Sí \\
\hline \multirow{2}{*}{ Castilla-La Mancha } & 1990 & L. 4/1990 & Sí \\
\hline & 2002 & L. 19/2002 & No \\
\hline \multirow{2}{*}{ Castilla y León } & 1997 & O. 28-1-1997 & Sí \\
\hline & 2014 & D. $18 / 2014$ & No \\
\hline
\end{tabular}




\begin{tabular}{|c|c|c|c|}
\hline & Año de creación & Norma de creación & ¿Hay AHP? \\
\hline \multirow{2}{*}{ Cataluña } & 1990 & D. 117/1990 & Sí \\
\cline { 2 - 4 } & 2001 & L. 10/2001 & Sí \\
\hline \multirow{2}{*}{ Comunidad Valenciana } & 1998 & L. 4/1998 & No \\
\cline { 2 - 4 } & 2005 & L. 3/2005 & No \\
\hline Extremadura & 2007 & L. 2/2007 & Sí \\
\hline \multirow{2}{*}{ Galicia } & 1989 & D. 307/1989 & No \\
\cline { 2 - 4 } & 2014 & L. $7 / 2014$ & No \\
\hline La Rioja & 1994 & L. 4/1994 & No \\
\hline Murcia & 2019 & D. 94/2019 & Sí \\
\hline \multirow{2}{*}{ Navarra } & 2005 & L. $14 / 2005$ & No \\
\cline { 2 - 4 } & 2007 & L. 12/2007 & No \\
\hline \multirow{2}{*}{ País Vasco } & 2000 & D. 232/2000 & No \\
\cline { 2 - 4 } & 2003 & D. 174/2003 & No \\
\hline
\end{tabular}

Este cuadro nos muestra que hay algún tipo de comisión calificadora en todas las Comunidades Autónomas, sin perjuicio del nombre que se les dé en cada caso, o de que asuman otras funciones añadidas. No obstante, hay que reseñar algunas particularidades.

En primer lugar, en Cataluña la normativa autonómica no menciona a los AHP, pero hay que tener en cuenta que el D. 110/1988 convierte los tres AHP en "arxius històrics” a secas — es decir, en la práctica, archivos históricos comarcales, aunque sin perjuicio de sus funciones respecto de la documentación estatal. Desde aquí, las comisiones calificadoras catalanas incluyen algún director de archivo histórico comarcal, sin que necesariamente tengan que ser los de Tarragona, Lleida o Girona. Sin embargo, esta comisión tiene una estructura interna bastante compleja, con varios grupos de trabajo y subcomisiones, en la que casi siempre aparece alguno de los responsables de estos tres centros.

La segunda peculiaridad la presenta La Rioja, donde la Ley 4/1994 crea el Consejo de Archivos, que asume funciones de valoración documental, pero el Decreto 3/2014, que regula el procedimiento de valoración, lo encomienda directamente a las Secretarías Generales de las Consejerías, con asesoramiento de archiveros, sin mencionar al Consejo, de manera que su comisión, que ni siquiera llegó a constituirse nunca, ha quedado desmantelada de hecho. Una situación similar ha venido desarrollándose en Murcia hasta la reciente aprobación del Decreto 94/2019 que crea y regula la correspondiente comisión calificadora. Aquí hay que señalar que no se prevé la presencia del AHP, pero sí del Archivo Regional, y es que desde $1996^{16}$ aquel no es más que una dependencia de este $\mathrm{y}$, aunque todavía persisten algunos detalles que recuerdan la situación anterior de "dos archivos en un edificio", ya hace algunos años que ambos archivos comparten

16 D. 62/1996, de organización de la Consejería de Cultura y Educación (BORM 17 de agosto). 
instalaciones, personas y prácticamente todos los aspectos de gestión, de manera que podríamos decir que, de hecho, el Archivo Regional ha absorbido al Histórico Provincial.

Otro caso singular son las Islas Baleares, que además es la comunidad que primero creó una comisión calificadora, aunque ciertamente sin que llegase a funcionar. Aquí contamos con que el Arxiu del Regne de Mallorca funciona como AHP, excepto para los protocolos notariales y las oficinas del Estado en Menorca, donde ejerce esta función el Arxiu Històric de Maón ${ }^{17}$. Ahora bien, mientras que este último ha sido constituido formalmente como tal AHP en $1977^{18}$, en el caso del archivo mallorquín hay que remitirse a la equivalencia entre "archivos históricos regionales” y archivos históricos provinciales que, ambiguamente, parece desprenderse del D. de 24 de julio de 1947. En todo caso, esta separación entre la documentación de Menorca y la del resto de las islas la encontramos igualmente para la documentación autonómica, tal como se establece en su Ley de Archivos y Patrimonio Documental, que incluso prevé la futura creación de un tercer archivo histórico en Ibiza. Por lo demás, cabe reseñar que en el convenio de cesión de la gestión de ambos archivos a la comunidad autónoma, el menorquín aparece mencionado simplemente como "Archivo Histórico de Mahón”19.

También debe hacerse mención del País Vasco, que no asumió la gestión de los AHP situados en su territorio hasta el Real Decreto 897/2011. Por tanto, es lógico que en su legislación archivística, incluyendo la relativa a la valoración de documentos autonómicos, ignorase a estos tres centros. Pero recientemente, por Decretos 86 a 88 de 2018, ha traspasado a su vez esta gestión a las correspondientes Diputaciones forales, en un acto de "meta-descentralización” tan interesante como inaudito. Al margen de lo que pueda ocurrir con una misma institución gestionando en cada provincia un "Archivo Histórico Provincial” y un "Archivo Histórico del Territorio", a nuestros efectos esto significa que los AHP vascos ni custodian ni custodiarán ningún documento de titularidad autonómica, y mucho menos intervendrán en su valoración.

Se observará, por último, que en esta lista faltan las dos ciudades autónomas y Madrid. En los casos de Ceuta y Melilla, su documentación es enteramente municipal y, por tanto, no hay intervención de AHP alguno en su gestión, si bien el Archivo Histórico de Melilla, creado en 1969, conserva los protocolos notariales de la ciudad ${ }^{20}$. En Madrid, como es sabido, no existe AHP y la documentación más característica de estos centros en el territorio madrileño se conserva en diferentes archivos.

Con todas estas prevenciones, volvamos a nuestro cuadro. Hay que insistir en que solo muestra la presencia formal de algún tipo de comisión calificadora en la legislación, pero en modo alguno significa que estas comisiones hayan llegado a funcionar de manera efectiva, entendiendo por esto que hayan emitido al menos una tabla de valoración. Como hemos visto, en algunos casos ni siquiera han llegado a

\footnotetext{
17 Así lo señala, por ejemplo, Gallo León (2002: 97), recogiendo una afirmación muy extendida.

18 RD 1192/1977, de 28 de marzo. (BOE 31 de mayo)

19 Res. de 14 de diciembre de 1984 (BOE 18 de enero de 1985)

20 Orden de 22 de octubre de 1969 (BOE 13 de noviembre)
} 
constituirse. Sea como fuere, podemos observar que la creación o re-creación de comisiones calificadoras autonómicas se ha realizado en tres etapas. La primera, que abarca desde la primera comisión, la de las Islas Baleares, hasta el final del siglo XX, que implica la creación de diez comisiones, de las que solo 4 contaban con los AHP en su composición. Los siguientes diez años, entre 2000 y 2009, se crearon 14 comisiones de las que cinco (Andalucía, Cataluña, Extremadura y las dos versiones de la cántabra) incluían a los AHP. En fin, en la última década se han creado cinco comisiones, y tres de ellas incluyen a los AHP, pero hay que tener en cuenta que una de ellas, la de Murcia, en realidad a quien menciona es al Archivo Regional de Murcia.

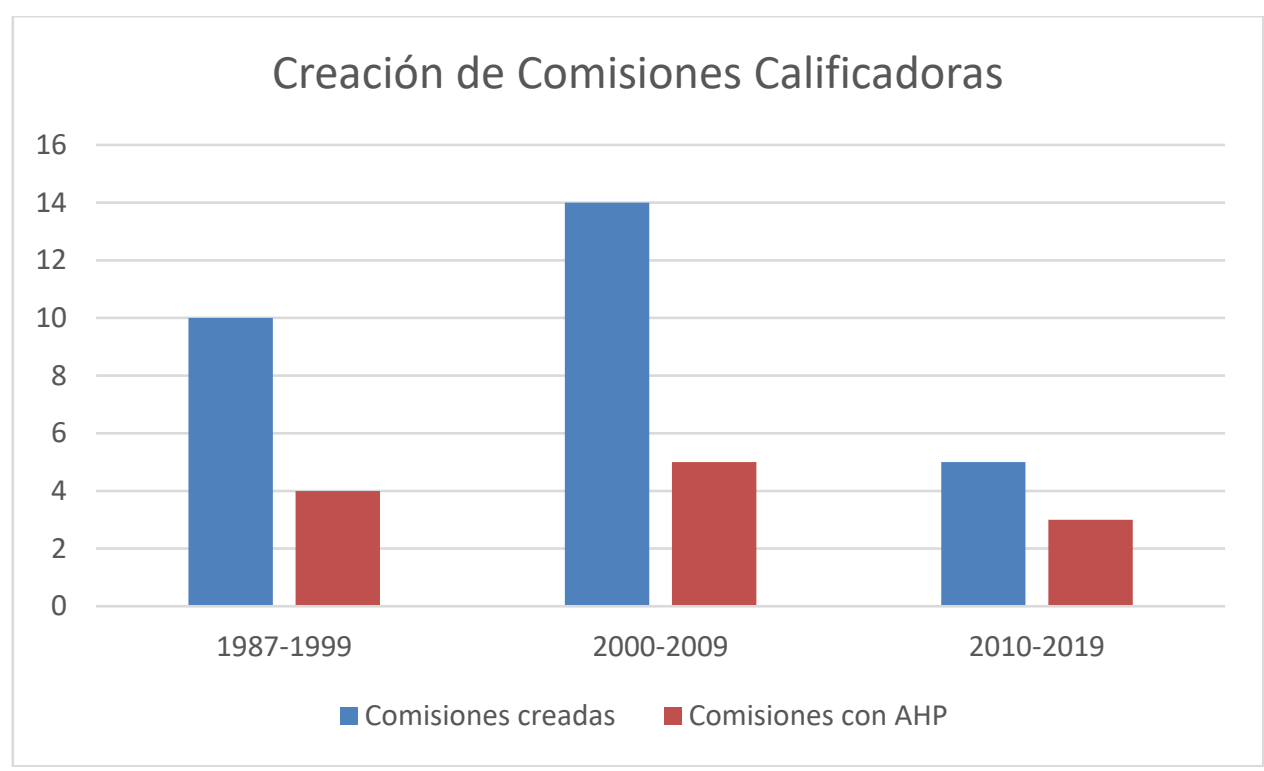

Figura 1. Fechas de creación de comisiones calificadoras.

Aún es necesario hacer un inciso sobre las dos Castillas, porque en estas comunidades la presencia de AHP en sus respectivas comisiones calificadoras estuvo garantizada por la normativa en su primera regulación, datada en los años 1990, pero en la actual, de 2002 y 2014, ya no se menciona a estos centros.

Así, pues, en la actualidad de 15 comunidades con comisión calificadora, la presencia de AHP está garantizada en seis casos, el $40 \%$. No olvidemos que en este grupo están incluidas, por un lado Cataluña, donde lo que está garantizada es la presencia de un archivo comarcal - en la práctica es raro que no intervenga algún archivero de los archivos históricos de Lleida, Tarragona o Girona, bien sea en el pleno o en los muchos grupos de trabajo-, y por otro lado las comunidades uniprovinciales, donde las funciones de AHP han sido asumidas de hecho por los archivos regionales, salvo en Cantabria.

Naturalmente, esto no significa que donde no esté expresamente previsto no puedan asistir a sus reuniones directores o representantes de estos centros en 
calidad de técnicos, expertos o cualquier otra denominación similar. Esto solo es posible saberlo buscando las disposiciones de nombramiento de los vocales o, si fuese posible, las actas de las reuniones de las comisiones de estas Comunidades Autónomas que no tienen estipulado la presencia del AHP en sus reuniones. Repasando tanto las páginas web de estas nueve comisiones, al igual que los boletines oficiales de sus respectivas comunidades autónomas, encontramos que solo la Comunidad Valenciana publica en su boletín oficial los nombramientos de los vocales de su comisión - desde el primer momento viene actuando como Secretario el director del Archivo del Reino de Valencia-, y solo Castilla-La Mancha publica las actas de sus sesiones ${ }^{21}$, a las que no asiste ningún representante de AHP. Podemos añadir que en la web de la Comisión General de Valoración Documental de las Islas Canarias se publica la composición de esta y sí aparece expresamente nombrado un representante de los AHP, aunque, como hemos visto, no aparece en las disposiciones legales ${ }^{22}$.

Es decir, que de 17 comunidades solo en ocho hay presencia de AHP en sus órganos de valoración documental, por distintas circunstancias ${ }^{23}$. No es una cifra excesiva, pero debe ser relacionada con la posición que los AHP tienen en los correspondientes sistemas archivísticos. Aunque el análisis detallado de este asunto nos llevaría ahora quizá demasiado lejos, no es lo mismo una comunidad que expresamente hace de sus AHP los repositorios para la documentación histórica, que aquella otra que ha optado por ignorarlos (País Vasco), camuflarlos (Cataluña) o asimilarlos a sus archivos autonómicos (Murcia o Asturias). Podrán añadirse los casos de las dos comunidades castellanas, en las que la desaparición de los AHP de sus respectivas comisiones calificadoras coincide con la aparición de los "archivos territoriales”, que vienen a ejercer algunas de las funciones que venían siendo atribuidas a aquellos (Flores Varela, 2018). Así pues, la presencia expresa de los AHP en los órganos de valoración autonómicos no responde al azar, sino que se alinea con una idea determinada sobre el papel que estos centros deben jugar en los sistemas autonómicos de archivos.

A modo de apéndice, podríamos reseñar que los AHP no parecen estar presentes tampoco en las Juntas de Expurgo de documentación judicial, pese a que suelen ser los receptores de la documentación judicial considerada de conservación permanente $^{24}$. Como sabemos, estas Juntas surgen del Decreto 937/2003 de Modernización de Archivos Judiciales, pero su puesta en marcha ha seguido ritmos distintos en las diferentes comunidades. Solo en nueve de ellas esta puesta en marcha se ha realizado de manera formal mediante la oportuna disposición legal ${ }^{25}$, mientras que en el resto estas Juntas operan basándose en el mencionado decreto de

21 https://archivos.castillalamancha.es/recursos/tablas-valoracion/Actas\%20de\%20la\%20Comisi\%C3\%B3n\% 20Calificadora. [Consulta: 27/11/2019]

22 http://www.gobiernodecanarias.org/cpj/dgmcs/temas/archivos/comision/composicion [Consulta 3/12/2019]

23 En Andalucía incluso se previó en 2004 la creación de un Grupo de Trabajo dedicado a estos centros (Díaz Díaz, 2010: 111), pero hoy este grupo no existe y no sé si ha llegado a funcionar

24 Para la situación de algunas Juntas de Expurgo hasta 2012, ver Muñoz Soro (2013: 127-128)

25 Ver la tabla realizada por Rodríguez Coya (2013: 186) y sus interesantes comentarios al respecto. A las Juntas de Expurgo que señala la autora como creadas con disposición propia hay que añadir las de Cantabria (O. PRE/99/2017) y Navarra (Ley 27/2015). 
2003. Otra cosa es su funcionamiento efectivo. Fátima Rodríguez $(2013,187)$ destaca las comunidades de Andalucía, Cataluña y Galicia como las que más y mejor vienen produciendo resoluciones de valoración de documentación judicial desde el primer momento, merced a su integración en un sistema archivístico coherente, pero en otros casos hay que esperar muchos años para que empiecen a producirse estos resultados. A modo de ejemplo, noticias indirectas sugieren que el año 2006 fue el que marcó el inicio de las Juntas de Expurgo de Castilla-La Mancha, Castilla y León (Muñoz Soro, 2013), Extremadura ${ }^{26}$ o La Rioja ${ }^{27}$, pero de todas ellas la de Castilla y León empezó a funcionar realmente en $2013^{28}$, la de Extremadura al año siguiente ${ }^{29}$ y la de Castilla-La Mancha en 2016 (Martínez García, 2018: 196); no he encontrado noticias de resoluciones de valoración de la Junta de Expurgo riojana.

Con norma propia o sin ella, en ningún caso se prevé la presencia de los AHP en las Juntas de Expurgo de documentos judiciales, pese a que el propio y reiterado Decreto de 2003 dispone que los documentos que estas juntas declaren de conservación permanente serán enviados a "la Administración competente en materia de patrimonio histórico”, es decir, las Comunidades Autónomas, dentro de las cuales son los AHP los que vienen recibiendo esta documentación. Sin embargo, eso no significa que nuestros archivos no estén de hecho presentes en estas Juntas. Así ocurre, por ejemplo, en Castilla y León, donde intervenía la directora del AHP de Burgos (Muñoz Soro, 2013, 128), o en Castilla-La Mancha, donde hace lo propio la de Albacete ${ }^{30}$. La excepción es Asturias, donde sí se prevé la presencia del Archivo Histórico de Asturias.

En conclusión, la tónica general es que los AHP sí intervengan en las comisiones o juntas que van a valorar documentos que, en muchos casos, si se declara su conservación permanente, irán a para a sus centros. Pero esta presencia solo es formal - es decir, no sujeta a la mera voluntad de los representantes políticos - en aproximadamente la mitad de las Comunidades Autónomas, y apenas en una Junta de expurgo de documentación judicial. Parece posible que se encuentren a los AHP en más comisiones, y especialmente también en las judiciales, pero en calidad de invitados, aunque esto no pasa de ser una apreciación que no puede basarse en datos completos porque no es habitual que se publiquen los nombres de las personas que integran las comisiones calificadora, juntas de expurgo u órganos similares en las comunidades autónomas, ni tampoco las actas de sus reuniones. Casi podríamos decir que nuestros centros están "de tapadillo" en estas comisiones.

\footnotetext{
26 “La Audiencia recibirá los nuevos estantes para el archivo el día 18”, El Periódico de Extremadura (14-42006). [Consulta: 27/11/2019]

27 “Los juzgados riojanos inician la reorganización de su archivo”, La Rioja (17-2-2006). [Consulta: 27/11/2019]

28 Anuncio de 3 de junio de 2013 (BOCYL 17)

29 Anuncio de 10 de julio de 2014 (DOE 29)

30 “Justicia destruirá miles de expedientes de juicios de faltas”, La Tribuna de Albacete (13-2-2016). [Consulta: 27/11/2019]
} 


\subsection{Las series documentales valoradas}

Una vez examinada la presencia de archiveros de los AHP en los órganos de valoración autonómicos, veamos si podemos decir algo sobre las series documentales valoradas por estos órganos y su influencia en los AHP. Hay que adelantar que no es posible realizar un estudio exhaustivo sobre el volumen de la documentación afectada en cada centro porque no se han publicado datos al respecto, con la excepción de Cataluña, que comentaré en su momento. Así pues, me centraré en las series documentales sin tener en cuenta su volumen. También conviene aclarar que he limitado la búsqueda hasta el año 2018 inclusive.

Para realizar esta tarea he utilizado, fundamentalmente, las propias normas que publican las tablas de valoración. Aunque generalmente podemos encontrar las tablas de valoración en las webs de las comisiones, lo habitual es que se omitan algunos datos importantes para nosotros, como el archivo destinatario final de la documentación o, en el caso de tablas de valoración revisadas, las versiones obsoletas. Sin embargo, es verdad que a veces las propias webs de las comisiones permiten enlazar con las publicaciones oficiales de las tablas. También hay que advertir que en ocasiones las comisiones publican no solo las tablas oficialmente aprobadas, sino también los estudios de valoración realizados pero aún no aprobados, lo que obliga a tener cierto cuidado en este punto; así ocurre, por ejemplo, en Asturias.

He considerado tanto las versiones actuales de las tablas como las obsoletas, y también he considerado como parte de las series documentales que afectan a los AHP aquellas consideradas "comunes" a toda la administración autonómica, bien sea porque así se dice expresamente o porque, al indicar su órgano productor, se dice "Todos los órganos de la Administración autonómica” o una expresión similar. Además de estas consideraciones generales, hay algunas peculiaridades de determinadas comunidades autónomas que deben ser también tenidas en cuenta:

- En el País Vasco, como he señalado, los AHP no custodian ni un solo documento autonómico, ni está previsto que lo vayan a hacer en un futuro próximo.

- En Cataluña la documentación a consultar es más abundante. Además del Diari Oficial de la Generalitat de Catalunya , la Comissió Nacional d'Access, Avaluació i Tría Documental (CNAATD) publica todos los años desde 1997 una Memoria de Actividades ${ }^{31}$. En sus tablas de valoración no se distingue entre órganos centrales y periféricos, ni tampoco se identifica si el archivo de destino será el Arxiu Nacional de Catalunya o un archivo comarcal, pero, entre otros muchos datos útiles, indica el número de metros lineales de documentación eliminada, especificando el órgano que ha realizado la eliminación, lo que permite saber cuánta documentación se ha eliminado de manera efectiva en cada uno de los tres archivos que nos interesan aquí.

31 https://cultura.gencat.cat/ca/departament/estructura_i_adreces/organismes/dgpc. [Consulta 27/11/2019]. 
- En las Islas Canarias y Extremadura no he encontrado ninguna tabla de valoración que señale como destino de la documentación el AHP, pese a que, como hemos visto, estos archivos están presentes en sus correspondientes comisiones calificadoras. Otro tanto ocurre en Galicia, aunque aquí la presencia de los AHP no está garantizada de derecho.

- En las comunidades uniprovinciales donde están funcionando de manera efectiva comisiones calificadoras, como es natural, las series de conservación permanente o los fragmentos de las de eliminación parcial irán a parar a sus respectivos archivos históricos. Conviene no olvidar que las comisiones de Cantabria y de Murcia se han constituido hace pocos meses, y que solo la primera de ellas ha llegado a reunirse alguna vez, en mayo de $2019^{32}$.

Por tanto, de las quince comisiones calificadoras, hay que restar las dos que aún no han empezado a funcionar y también las tres que, de un modo u otro, no se ocupan claramente de documentación cuyo destino final sea el AHP. Tampoco utilizaré la vasca ni la catalana, por las razones que acabo de exponer. Nos quedan, pues, ocho comisiones calificadoras con las que trabajar.

Tabla 2. Comparación entre el total de series valoradas por las comisiones calificadoras autonómicas y las que afectan a AHP

\begin{tabular}{|l|r|r|r|}
\hline & Total series & $\begin{array}{l}\text { Series } \\
\text { provinciales }\end{array}$ \\
\hline Andalucía & 278 & 95 & $\mathbf{\%}$ \\
\hline Aragón & 1180 & 264 & $22,37 \%$ \\
\hline Asturias & 823 & 823 & $100,00 \%$ \\
\hline Baleares & 245 & 245 & $100,00 \%$ \\
\hline Castilla-La Mancha & 26 & 16 & $61,53 \%$ \\
\hline Castilla y León & 889 & 625 & $70,30 \%$ \\
\hline Comunidad Valenciana & 214 & 79 & $36,92 \%$ \\
\hline Navarra & 627 & 627 & $100,00 \%$ \\
\hline TOTAL & $\mathbf{4 2 7 7}$ & $\mathbf{2 7 6 8}$ & $\mathbf{6 4 , 7 2 \%}$ \\
\hline
\end{tabular}

Como vemos, pues, estas comisiones han publicado casi 4.300 tablas de valoración de series documentales, de las que algo menos de 2.800 corresponden a series que irían a parar a los AHP, es decir, el $65 \%$ de las series. Si incluyésemos las tres comunidades que no mencionan los AHP tendríamos un total de 4.616 series, con lo que la proporción sería levísimamente inferior. De entre estas comunidades, y al margen lógicamente de las uniprovinciales, encontramos que la

32 https://www.europapress.es/cantabria/noticia-cultura-reune-primera-vez-comision-patrimonio-documental20190513135356.html [Consulta 27/11/2019]. 
Comunidad Valenciana, Andalucía y Aragón presentan unas proporciones similares, entre el 20-35 \%, mientras que las dos Castillas oscilan entre el 60 y el $70 \%$.

¿Qué podemos concluir de aquí? Evidentemente, que los AHP no son prioridad para las comisiones de valoración autonómicas. Salvo excepciones -las dos Castillas - las comunidades se dedican más a la documentación producida por sus servicios centrales, incluso si en sus órganos de calificación se incluyen expresamente los AHP, lo mismo que, como hemos visto, ocurre en la Administración General del Estado.

Todavía podemos profundizar un poco más en nuestro análisis. Centrémonos ahora solo en las series valoradas que implican a los AHP y fijémonos en el dictamen que se les aplica, es decir, en si son series destinadas a la destrucción, a la eliminación parcial o a la conservación permanente. El cuadro siguiente resume los datos al respecto.

Tabla 3. Dictámenes de valoración a las series que afectan a AHP en las comisiones calificadoras autonómicas

\begin{tabular}{|c|c|c|c|c|c|c|c|}
\hline \multirow[b]{2}{*}{ Andalucía } & \multirow[t]{2}{*}{ Eliminación } & \multirow{2}{*}{\begin{tabular}{|r|}
$\begin{array}{c}\text { C. } \\
\text { Parcial }\end{array}$ \\
69 \\
\end{tabular}} & \multirow{2}{*}{$\begin{array}{r}\text { Conservación } \\
18 \\
\end{array}$} & \multicolumn{2}{|c|}{ \% elim. } & \multirow{2}{*}{$\begin{array}{r}\text { \% parcial } \\
18,95 \% \\
\end{array}$} & \multirow{2}{*}{$\begin{array}{r}\text { \% conserv. } \\
8,42 \% \\
\end{array}$} \\
\hline & & & & 8 & $72,63 \%$ & & \\
\hline Aragón & & 205 & 5 & 54 & $77,65 \%$ & $1,89 \%$ & $20,45 \%$ \\
\hline Asturias & & 267 & 125 & 431 & $32,44 \%$ & $15,19 \%$ & $52,37 \%$ \\
\hline Baleares & & 61 & 74 & 110 & $24,90 \%$ & $30,20 \%$ & $44,90 \%$ \\
\hline $\begin{array}{l}\text { Castilla-La } \\
\text { Mancha }\end{array}$ & & 16 & & & $100,00 \%$ & $0,00 \%$ & $0,00 \%$ \\
\hline $\begin{array}{l}\text { Castilla y } \\
\text { León }\end{array}$ & & 504 & 72 & 49 & $80,64 \%$ & $11,52 \%$ & $7,84 \%$ \\
\hline $\begin{array}{l}\text { C. } \\
\text { Valenciana }\end{array}$ & & 53 & 2 & 24 & $67,09 \%$ & $2,53 \%$ & $30,38 \%$ \\
\hline Navarra & & 356 & 114 & 157 & $56,78 \%$ & $18,18 \%$ & $25,04 \%$ \\
\hline TOTAL & & 1525 & 410 & 833 & $55,09 \%$ & $14,81 \%$ & $30,09 \%$ \\
\hline
\end{tabular}

En conjunto, pues, más de la mitad de las series se destinan a la destrucción total, es decir, que no llegarán a entrar en los AHP, o si ya han llegado serán destruidas, excepto los muestreos reglamentarios. Del resto, un $30 \%$ se destinan a conservación permanente y las demás son valoradas como de eliminación parcial. Sin embargo, una observación más detallada de estas cifras revela rápidamente profundas diferencias entre comunidades. En efecto, por un lado Andalucía y Castilla y León no llegan al 10 \% de series declaradas de conservación permanente, e incluso Castilla-La Mancha simplemente ha declarado de eliminación total todas las series que ha valorado hasta el momento, aunque también es cierto que esta es la comunidad que menor número de series valoradas presenta. Por su parte, Asturias o Baleares rondan el $50 \%$ de series a conservar. Sin duda, esta querencia por la conservación de series debe relacionarse con el hecho de ser dos 
comunidades uniprovinciales, donde las funciones de archivo general autonómico y de archivo provincial se unen en un mismo centro. De hecho, en conjunto las tres comunidades uniprovinciales acaparan más de tres cuartas partes de las series de eliminación parcial y casi el 84 \% de las de conservación permanente. Todo esto indica que, cuando las comisiones calificadoras se ocupan de la documentación provincial es, fundamentalmente, para eliminarla, opción que resulta, hasta cierto punto, lógica si pensamos que, hoy por hoy, las provincias como tales no tienen poder político alguno, ni siquiera de hecho en su única institución propia, las Diputaciones Provinciales — que, por lo demás, mantienen celosamente su propio archivo y son consideradas administraciones locales a todos los efectos, incluyendo el que aquí nos ocupa - sino que más bien son meros engranajes administrativos, simples lugares de ejecución del poder, no de auténticas tomas de decisión (Ponce Alberca, 2016: 96-97; Flores Varela, 2018: 236). No obstante, queda un resquicio de duda. Como bien señala Mateo Páez para el caso andaluz, "tenemos por un lado un enorme número de tablas de valoración aprobadas cuya aplicación es muy reducida o afecta a un número despreciable de unidades de instalación, y por otro un número escasísimo de tablas de valoración que son aplicadas en muchas ocasiones y para un enorme volumen documental” (Páez García, 2010: 89). Algunos años antes, Lluis Cermeno había detectado también que la mayor parte de los centros no aplicaban sus tablas de valoración documental o esta aplicación tenía una incidencia práctica mínima, mientras que unos pocos centros acumulaban la mayor parte de las eliminaciones (Cermeno Martorell, 2003: 170).

Más allá de estos estudios, que no dejan de ser localizados en el tiempo y en el espacio, no sabemos en realidad en qué medida estas tablas de valoración están influyendo en la documentación que se conserva en los AHP. A título ilustrativo, puedo indicar que en el AHP de Toledo las decisiones de la CSCDA permitieron realizar eliminaciones de documentación por primera vez en 2017, con 77 metros eliminados, cantidad que se elevó a 116 metros en 2018, en total aproximadamente el $2 \%$ del volumen total de documentación del archivo.

Sólo en Cataluña contamos con datos continuados en el tiempo. En las memorias anuales de la comisión catalana se reflejan los metros lineales eliminados y el archivo que ha realizado la eliminación, por lo que es posible establecer una comparación entre los metros eliminados totales y los eliminados en los AHP. Sin embargo, como hemos visto, este caso es bastante peculiar debido a su estructura administrativa comarcal y a que, además, sus tablas de evaluación, tal como han sido publicadas, no diferencian entre órganos de la administración central autonómica y órganos de la administración periférica autonómica, de manera que no sería posible relacionar el número de series valoradas con el volumen de documentación eliminada en los tres archivos catalanes que nos interesan aquí. Podría intentarse un ejercicio de reconstrucción hipotética, acumulando las eliminaciones de todos los archivos comarcales de cada provincia, es decir, calculando la documentación que se hubiera destruido en los archivos de Girona, Lleida y Tarragona en caso de haber funcionado como los demás AHP respecto de la documentación autonómica, pero tal ejercicio no sería más que una elucubración demasiado alejada de la realidad. 
No obstante, podemos acercarnos a los datos globales en Cataluña, es decir, el total de metros eliminados y los correspondientes a sus órganos periféricos, incluyendo los archivos comarcales, aun sin distinguir entre provincias. A partir de las propias memorias de la $\mathrm{CNAATD}^{33}$ he elaborado las siguientes tabla y gráfico indicando el número total de metros lineales eliminados, los que corresponden a órganos de la administración periférica de la Generalitat y los correspondientes porcentajes:

Tabla 4. Volumen total y periférico de la documentación eliminada por la Generalitat de Catalunya

\begin{tabular}{|r|r|r|r|}
\hline & Total & Órganos periféricos & \multicolumn{1}{c|}{$\%$} \\
\hline 1997 & 648,82 & 280,00 & $43,16 \%$ \\
\hline 1998 & 389,27 & & $0,00 \%$ \\
\hline 1999 & $1.641,71$ & 483,00 & $29,42 \%$ \\
\hline 2000 & $1.365,34$ & 398,90 & $29,22 \%$ \\
\hline 2001 & $1.470,95$ & 61,50 & $4,18 \%$ \\
\hline 2002 & $1.421,49$ & 292,45 & $20,57 \%$ \\
\hline 2003 & $2.877,46$ & 296,80 & $10,31 \%$ \\
\hline 2004 & $4.363,56$ & 824,16 & $18,89 \%$ \\
\hline 2005 & $7.135,86$ & $1.393,42$ & $19,53 \%$ \\
\hline 2006 & $4.254,52$ & 773,26 & $18,18 \%$ \\
\hline 2007 & $4.583,42$ & $1.028,19$ & $22,43 \%$ \\
\hline 2008 & $4.462,94$ & $2.062,17$ & $46,21 \%$ \\
\hline 2009 & $7.835,67$ & $3.052,42$ & $38,96 \%$ \\
\hline 2010 & $5.914,04$ & $2.223,96$ & $37,60 \%$ \\
\hline 2011 & $11.454,44$ & $3.899,16$ & $34,04 \%$ \\
\hline 2012 & $7.272,84$ & $1.830,44$ & $25,17 \%$ \\
\hline 2013 & $8.592,90$ & $1.887,68$ & $21,97 \%$ \\
\hline 2014 & $9.152,37$ & $3.883,11$ & $42,43 \%$ \\
\hline 2015 & $7.296,57$ & $1.600,24$ & $21,93 \%$ \\
\hline 2016 & $7.826,38$ & 477,37 & $6,10 \%$ \\
\hline 2017 & $17.027,68$ & $\mathbf{3 4 . 6 8 2 , 4 2}, 60 \%$ \\
\hline TOTAL & $\mathbf{1 1 6 . 9 8 8 , 2 3}$ & & \\
\hline
\end{tabular}

Así pues, en conjunto algo menos del 30 \% del volumen de documentación eliminada en Cataluña como consecuencia de la actividad de la CNAATD desde

33 Las memorias de la CNAATD están disponibles en

https://cultura.gencat.cat/ca/departament/estructura_i_adreces/organismes/

¡dgpc/temes/arxius_i_gestio_documental/cnaatd/accio_de_la_cnaatd/memos/. [Consulta: 27/11/2019].

Algunos años (1998) no se indica el número de metros lineales eliminados 
1997 afecta a órganos periféricos de su administración autonómica, es decir, es documentación que no ha llegado a ingresar en los archivos comarcales o que, si lo hizo, ha sido eliminada allí. El total supera los 34.600 metros lineales de documentación. En cuanto a su evolución temporal, se observan sobre todo grandes altibajos, pero quizá una tendencia general a aumentar la proporción de metros lineales eliminados en los órganos periféricos hasta 2008, en que se alcanza el máximo de 46,2 \% de la documentación eliminada ese año; desde entonces, los altibajos han sido aún más pronunciados, pero puede observarse un cierto descenso en esta proporción ${ }^{34}$.

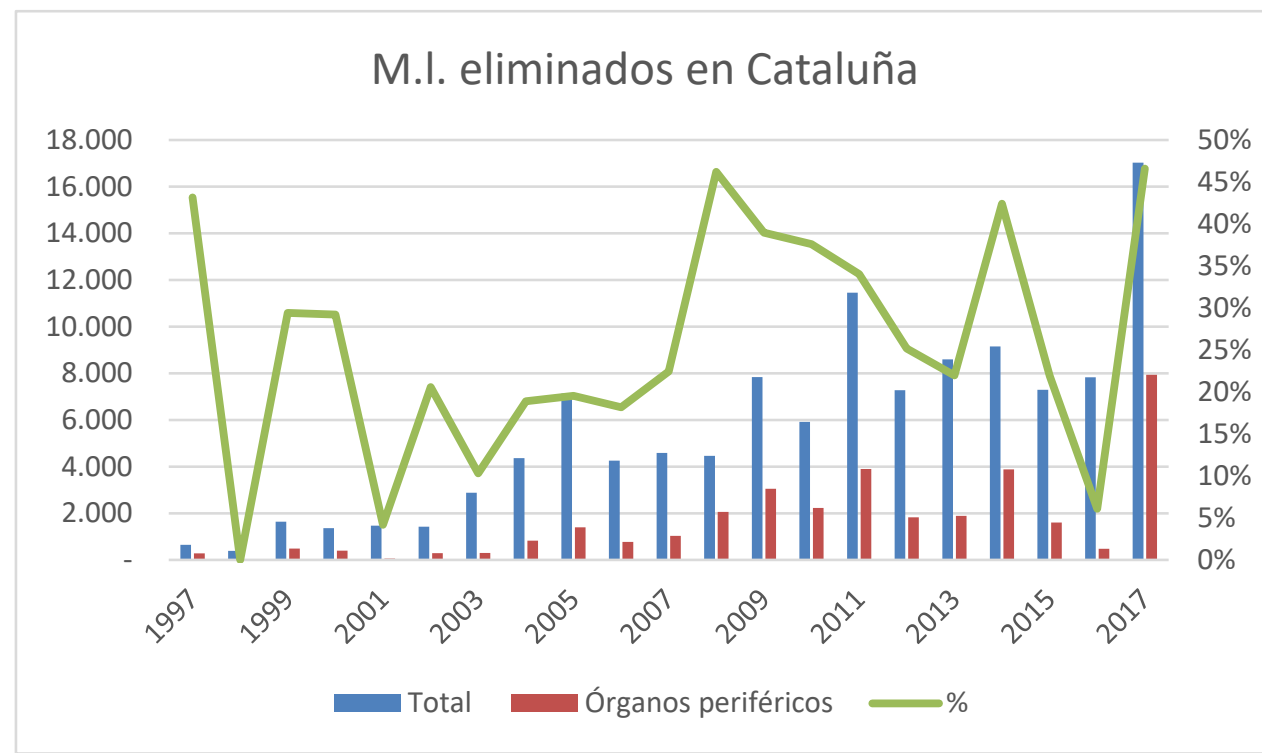

Figura 2. Volumen total y periférico de la documentación eliminada por la Generalitat de Catalunya

\section{Conclusiones}

Este recorrido por normativas, cifras y datos lleva, en mi opinión, a una conclusión clara: los AHP están actualmente infrarrepresentados en los órganos de valoración documental españoles, a pesar de ser los destinatarios de buena parte de la documentación que esos mismos órganos declaren de conservación permanente. En la Administración General del Estado se tardaron seis años en escuchar la voz de estos centros después de que se empezase a disponer sobre la documentación que debía entrar o no en ellos. Apenas la mitad de las comunidades autónomas incluyen

34 La cifra de 2017, última reseñada en las memorias de la CNAATD, es sorprendentemente alta, sobre todo después de una no menos sorprendentemente baja el año anterior. La mayor parte de los metros eliminados en 2017 proceden de dos organismos, las Oficinas Liquidadoras de Granollers y Sabadell, que acumulan juntas 2.934,07 metros, el 37 \% del total del año. Todo apunta, pues, a una situación coyuntural en la que, probablemente, quedó para 2017 lo que no se había eliminado el año anterior. 
a los AHP, de hecho o de derecho en sus órganos de valoración documental aunque la mayoría también les señalan como destinatarios de su documentación histórica. Es decir, que apenas pueden opinar sobre decisiones que les afectan profundamente.

Lo que sí me parece claro es que, cuando se les permite intervenir de forma activa, los archiveros de los AHP muestran una capacidad de trabajo al menos comparable a la de sus compañeros de los archivos centrales de consejerías o ministerios, como demuestran los datos sobre series valoradas, tanto en el ámbito estatal como autonómico. También apunta en esta dirección la presencia de archiveros de AHP en órganos de valoración en los que, aparentemente, no se espera su presencia, incluyendo algunas juntas de expurgo judiciales. Sea en forma de asesores, miembros de libre designación o simplemente asistentes, lo cierto es que se sigue echando mano de estos profesionales pero sin que esta presencia acabe de ser publicitada claramente, casi de forma vergonzante.

Todo ello nos lleva a pensar que la posición de los AHP en los sistemas de valoración documental no es más que un reflejo de una situación general en la que se encuentran estos centros, autonómicos pero estatales, históricos pero intermedios, aparentemente al margen del mainstream de la archivística actual pero a la vez siempre presentes. En mi opinión, esta situación intermedia entre diferentes elementos es la principal debilidad de los AHP, pero también su mayor fortaleza y sería necesario aprovecharla para reforzar su capacidad de decisión en las valoraciones documentales. Un ejemplo puede ser el grupo de trabajo creado en la CSCDA, cuyos resultados han sido inmediatos y más que notables. En esta línea, creo que los AHP están en condiciones de hacer propuestas de valoración coordinadas entre diferentes administraciones aprovechando su relativa facilidad de comunicación entre sí, con o sin grupos de trabajo más o menos formales. Estar en la "tierra media" puede significar el aislamiento, pero también puede convertirnos en puentes. Desde luego, creo que merece la pena trabajar por esta segunda opción.

\section{ANEXO: RELACIÓN DE LEGISLACIÓN AUTONÓMICA BÁSICA}

\section{- Andalucía}

- DECRETO 73/1994, de 29 de marzo, por el que se aprueba el Reglamento de Organización del Sistema Andaluz de Archivos y desarrollo de la Ley 3/1984, de 9 de enero, de Archivos (BOJA 18 de mayo).

- DECRETO 97/2000, de 6 de marzo, por el que se aprueba el Reglamento del Sistema Andaluz de Archivos, y desarrollo de la Ley 3/1984, de 9 de enero, de Archivos (BOJA 11 de abril). Desarrollado por:

- $\quad$ ORDEN de 7 de julio de 2000, por la que se regula el funcionamiento de la Comisión Andaluza calificadora de documentos administrativos y los procesos de identificación, valoración y selección documentales (BOJA 1 de agosto).

- ORDEN de 19 de marzo de 2001, por la que se nombra al Presidente y a los miembros de la Comisión Andaluza Calificadora de Documentos Administrativos (BOJA 17 de abril). 
- $\quad$ ORDEN de 25 de julio de 2005, por la que nombra a la Presidenta y a los miembros de la Comisión Andaluza Calificadora de Documentos Administrativos (BOJA 7 de octubre)

- LEY 7/2011, de 3 noviembre, de Documentos, Archivos y Patrimonio Documental de Andalucía (BOJA 11).

- ORDEN de 1 de septiembre de 2004, por la que se constituye la Junta de Expurgo de la Comunidad Autónoma de Andalucía, en aplicación de lo dispuesto por el Real Decreto 937/2003, de 18 de julio, de modernización de los archivos judiciales (BOJA 20).

\section{- Aragón}

- DECRETO 12/1993, de 9 de febrero, por el que se crea el Archivo de la Administración de la Comunidad Autónoma de Aragón y se regula su organización y funcionamiento (BOA 8 de marzo).

- DECRETO 115/2013, de 9 de julio, del Gobierno de Aragón, por el que se constituye la Junta de Expurgo de Documentos Judiciales y se regula su régimen de funcionamiento, en el ámbito de la Comunidad Autónoma de Aragón (BOA 19).

\section{- Asturias}

- DECRETO 21/1996, de 6 de junio, por el que se regula la organización y funcionamiento del sistema de archivos administrativos del Principado de Asturias (BOPA 28). Desarrollado por:

- RESOLUCION de 3 de marzo de 1999, de la Consejería de Cooperación, por la que se desarrolla el Decreto 21/96, de 6 de junio, regulador del sistema de archivos administrativos del Principado de Asturias (BOPA 24).

\section{- Cantabria}

- DECRETO 7/2000, de 2 de marzo, por el que se regula la composición y el funcionamiento de las Comisiones Técnicas en materia de Patrimonio Cultural (BOC 8).

- LEY 3/2002, de 28 de junio de Archivos de Cantabria (BOC 9 de julio). Desarrollada por:

- Decreto 69/2018, de 23 de agosto, por el que se aprueba el Reglamento de la Comisión de Patrimonio Documental de Cantabria (BOC 3 de septiembre).

- ORDEN PRE/99/2017, de 22 de diciembre, por la que se constituye la Junta de Expurgo del Archivo Judicial de Gestión de la Comunidad Autónoma de Cantabria (BOC 5 de enero de 2018).

\section{- Castilla-La Mancha}

- LEY 4/1990, de 30 de mayo, del Patrimonio Histórico de Castilla-La Mancha (DOCM 13 de junio). Desarrollado por:

- DECRETO 134/1996, de 19 de noviembre, por el que se organiza la Comisión Calificadora de Documentos de Castilla-La Mancha y se regula su composición y funcionamiento (DOCM 22).

- LEY 19/2002, de 24 de octubre, de archivos públicos de Castilla-La Mancha (DOCM 15 de noviembre). Desarrollada por:

- DECRETO 26/2017, de 28 de marzo, por el que se regula la composición y funcionamiento de la Comisión Calificadora de Documentos de Castilla-La Mancha y el procedimiento de eliminación de documentos de los archivos 
públicos del Subsistema de Archivos de los Órganos de Gobierno y de la Administración de la Junta de Comunidades de Castilla-La Mancha (DOCM 4 de abril).

- Castilla y León

- DECRETO 115/1996, de 2 de mayo, por el que se aprueba el Reglamento del Sistema de Archivos de Castilla y León (BOCYL 8). Desarrollado por:

- ORDEN de 28 de enero de 1997, de la Consejería de Educación y Cultura, por la que se crea la Comisión Calificadora de Documentos de Castilla y León y se regula su composición y funcionamiento (BOCYL 4 de febrero).

- DECRETO 18/2014, de 24 de abril, por el que se crea y regula el Consejo de Archivos, Bibliotecas y Centros Museísticos de Castilla y León (BOCYL 28).

\section{- Cataluña}

- DECRETO 117/1990, de 3 de mayo, sobre evaluación y selección de documentos de la Administración pública (DOGC 25).

- Ley 10/2001, de 13 de julio, de archivos y gestión de documentos (DOGC 24). Desarrollada por:

- DECRETO 13/2008, de 22 de enero, sobre acceso, evaluación y selección de documentos (DOGC 25)

- ORDEN CMC/311/2010, de 14 de mayo, de los grupos de trabajo de la Comisión Nacional de Acceso, Evaluación y Selección Documental (DOGC 1 de junio).

- ORDEN JUS/552/2006, de 30 de octubre, por la que se constituye y se regula la Junta de Expurgo de la Documentación Judicial de Cataluña y se aprueban las normas y los modelos de relaciones documentales de transferencia de documentación judicial (DOGC 24 de noviembre).

\section{- Comunidad Valenciana}

- LEY 4/1998, de 11 de junio, del Patrimonio Cultural Valenciano (DOGV 18).

- LEY 3/2005, de 15 de junio, de Archivos (DOGV 16). Desarrollada por:

- DECRETO 189/2005, de 2 de diciembre, por el que se regula la Junta Calificadora de Documentos Administrativos y el procedimiento de valoración, conservación y eliminación del patrimonio documental de los archivos públicos (DOGV 7).

- DECRETO de 50/2018, de 27 de abril, por el que se regula la gestión documental, la organización y el funcionamiento de los archivos de la Generalitat. (DOCV 7 de mayo).

- DECRETO 61/2006, de 12 de mayo, por el que se aprueba el Reglamento de Funcionamiento de la Junta de Expurgo de Documentos Judiciales y se crea el Fondo Histórico Judicial de la Comunitat Valenciana (DOGV 16).

\section{- Extremadura}

- LEY 2/2007, de 12 de abril, de Archivos y Patrimonio Documental de Extremadura (DOE 26). Desarrollada por:

- DECRETO 38/2012, de 16 de marzo, por el que se constituye el Archivo Central y se regula la Comisión de Valoración de Documentos de la Junta de Extremadura (DOE 22). 


\section{- Galicia}

- DECRETO 307/1989, de 23 de noviembre, por el que se regula el sistema de archivos y el patrimonio documental de Galicia (DOG 1 de febrero de 1990).

- LEY 7/2014, de 26 de septiembre, de archivos y documentos de Galicia (DOG 7 de octubre). Desarrollada por:

- DECRETO 15/2016, de 14 de enero, que regula la composición y el funcionamiento del Consejo de Evaluación Documental de Galicia y el procedimiento de evaluación y selección de documentos (DOG 19 de febrero).

- DECRETO 46/2009, de 26 de febrero, sobre los archivos judiciales territoriales y la Junta de Expurgación de la Documentación Judicial de Galicia (DOG 11 de marzo).

\section{- Islas Baleares}

- DECRETO 14/1987, de 5 de marzo, de creación y regulación del Archivo Administrativo General del Gobierno Balear (BOIB 24).

- LEY 15/2006, del 17 de octubre, de archivos y patrimonio documental de las Illes Balears (BOIB 28). Desarrollado por:

- $\quad$ Decreto 99/2010, de 27 de agosto, por el cual se regulan los archivos de la Administración de la Comunidad Autónoma de las Illes Balears y de las entidades que integran su sector público instrumental (BOIB 7 de septiembre).

\section{- Islas Canarias}

- DECRETO 76/2003, de 12 de mayo, por el que se aprueba el Reglamento del sistema de gestión documental y organización de los archivos de la Administración Pública de la Comunidad Autónoma de Canarias (BOC 23).

- DECRETO 160/2006, de 8 de noviembre, por el que se aprueba el Reglamento del Sistema de gestión documental y organización de los archivos dependientes de la Administración Pública de la Comunidad Autónoma de Canarias (BOC 16).

- DECRETO 45/2013, 18 abril, por el que se crea la Junta de Expurgo de Documentos Judiciales de Canarias (BOC 26 de abril).

\section{- La Rioja}

- LEY 4/1994, de 24 de mayo, de Archivos y Patrimonio Documental de La Rioja (BOR 28). Desarrollada por:

- DECRETO 66/1994, de 24 noviembre, por el que se regula el Consejo de Archivos de La Rioja (BOR 1 de diciembre).

- DECRETO 3/2014, de 17 de enero, por el que se regula el procedimiento de valoración para la conservación o eliminación de los documentos que integran el Patrimonio Documental de La Rioja (BOR 22).

\section{- Murcia}

- LEY 6/1990, de 11 de abril, de Archivos y Patrimonio Documental de la Región de Murcia (BORM 22 de mayo)

- ORDEN de 8 de junio de 2011, de la Consejería de Educación, Formación y Empleo, por la que se crea y regula la Comisión Calificadora de Documentos Administrativos de la citada Consejería (BORM 22). 
- DECRETO 94/2019, de 22 de mayo, por el que se crea y regula la Comisión Calificadora de Documentos Administrativos de la Región de Murcia y el procedimiento de valoración y eliminación documental (BORM 31).

- Navarra

- LEY FORAL 14/2005, de 22 de noviembre, del Patrimonio Cultural de Navarra (BON 25). Desarrollada por:

- DECRETO FORAL 75/2006, de 30 de octubre, por el que se aprueba el reglamento que regula la composición, organización y funcionamiento de la Comisión de Evaluación Documental (BON 20 de noviembre).

- LEY FORAL 12/2007, de 4 de abril, de Archivos y Documentos (BON 18).

- DECRETO FORAL 27/2015, de 6 de mayo, por el que se constituye la Junta de Expurgo de Documentos Judiciales de Navarra (BON 22).

\section{- País Vasco}

- DECRETO 232/2000, de 21 de noviembre, por el que se aprueban el Reglamento de los Servicios de Archivo y las normas reguladoras del Patrimonio Documental del País Vasco (BOPV 11 de diciembre).

- DECRETO 174/2003, de 22 de julio, de organización y funcionamiento del Sistema de Archivo de la Administración Pública de la Comunidad Autónoma de Euskadi (BOPV 22 de agosto).

- ORDEN de 19 de diciembre de 2005, de la Consejera de Hacienda y Administración Pública, sobre el procedimiento para la identificación y valoración documental, y el funcionamiento de la Comisión de Valoración, Selección y Acceso a la Documentación de la Administración Pública de la Comunidad Autónoma de Euskadi (BOPV 17 de febrero de 2006).

\section{Referencias bibliográficas}

Archivo General de la Administración del Principado de Asturias (2018). Normas de la Comisión de calificación y Valoración de Documentos Administrativos del principado de Asturias conforme al decreto 21/96 de Organización y funcionamiento del Sistema de Archivos Administrativos y su desarrollo. < https://ria.asturias.es/RIA/bitstream/ 123456789/7042/3/Archivo.pdf $>$ [Consulta 27/11/2019]

Cermeno Martorell, Ll. (2003). El sistema de evaluación de documentos de Cataluña. Tabula, 6, 153-182

Cermeno Martorell, Ll. (2012). La acción en materia de acceso de la Comisión Nacional de Acceso. Evaluación y Selección Documental de Cataluña. Tabula, 15, 197-210

Conde Villaverde, M. L. (2016). Evolución y desarrollo de la práctica archivística: La aplicación de nuevos conceptos mediante una nueva metodología para alcanzar nuevos objetivos. Tria, 20, 123-146.

Díaz Díaz, M. J. (2019). La valoración y el modelo de selección documental en Andalucía desde la experiencia en los grupos de trabajo. Tría, 16, 105-126

Flores Varela, C. (2018). Los Archivos Históricos Provinciales y la construcción de la memoria colectiva. Tabula, 21, 235-255

Garmendia Ruíz, B. (2000). La valoración documental en el sistema archivístico de Castilla y León. Subsistema de la documentación autonómica. Boletín ACAL, 10, 35, 29-31 
González Corral, I. (2012). El papel de las comisiones calificadoras en relación al derecho de acceso a documentos y archivos. Tabula, 15, 187-195.

López Fernández, J. R.; Rodríguez-Segade Vázquez, A. (2018). A valoración de documentos nas organización. O Concello de Avaliación Documental de Galicia, Administración \& Cidadanía. Revista da Escola Galega de Administración Pública, 13 (2), 95-110

Martínez García, L. (2016). Políticas públicas y archivos en Castilla-La Mancha, 19832015. En: Actas das II Xornadas Olga Gallego de Arquivos. Os arquivos da Administración local: política, planificación e sistemas fronte ao cambio. [S.l.]: Fundación Olga Gallego, 167-345

Muñoz Soro, J. F. (2013). La gestión y valoración de los documentos judiciales en el nuevo contexto tecnológico. Zaragoza: Universidad de Zaragoza

Páez García, M. (2010). La valoración y selección documental en Andalucía: pasado, presente y futuro. Tria, 16, 75-104

Ponce Alberca, J. (2016). Por la piel provincial de España: estado, política y administración local. En: Barrajón, J.M.; Castellanos, J. A. (coords.). La provincia: realidad histórica e imaginario cultural. Madrid: Sílex, 75-100

Rodríguez Coya, F. (2013). Las juntas de expurgo en el contexto de la gestión de documentos judiciales. En: González Cachafeiro, J.(coord.). Jornadas Archivando: la valoración documental. León: Fundación Sierra-Pambley, 182-190

Ruiz Cagigal, A. (2017). La solución de las comisiones calificadoras de documentos administrativos. Consultor de los ayuntamientos y de los juzgados, 14, 1816-1831

Tarraubella i Mirabet, X. (2003). El Grupo de Trabajo de documentación municipal de obras y urbanismo de la Comisión Nacional de Valoración y Selección Documental de la Generalitat de Catalunya: presentación de la experiencia. En: IV Jornadas de Archivos Municipales de Cantabria. Santander: Asociación para la Defensa del Patrimonio Documental y Bibliográfico de Cantabria, 91. 